Estilos do cuidado - A psicanálise e o traumático.Daniel Kupermann São Paulo, SP: Zagodoni, 2017, 176 págs.

\title{
Do trauma à ternura: os fundamentos da clínica do cuidado
}

\section{From trauma to tenderness:}

the foundations of the care in psychoanalisis

O livro de Daniel Kupermann, Estilos do cuidado - A psicanálise e o traumático, sela um percurso que deriva de uma busca constante pelas bases fundadoras do pensamento freudiano, trazendo ao leitor o conhecimento de algo do que ficou 'recalcado', ou no mínimo esquecido, do próprio métier psicanalítico. Mesmo aos já iniciados, Daniel faz revelações surpreendentes dos conflitos existentes nas 'alcovas' da arriscada empreitada pela sexualidade inconsciente. Alguns exemplos pitorescos: para além da paixão já conhecida de todos, Anna O. 'fez' uma gravidez imaginária, atribuindo a paternidade a Breuer,

* Universidade Federal Fluminense - UFF (Niterói, RJ, Br). 


\section{RESENHAS BIBLIOGRÁFICAS}

que acabou fugindo da paciente para engravidar sua esposa. Assim, deixou a Freud a responsabilidade e a chance de fecundar com ela a noção de "transferência" e, consequentemente, a "peste" pela qual ainda estamos contaminados; Daniel retoma também, com detalhes, o ressentimento de Ferenczi por não ter sido interpretado por Freud em sua "transferência negativa", levando-o a praticamente abolir a interpretação como técnica princeps e a apostar na "linguagem da ternura" como veículo compreensivo primordial na relação com o outro, infantil em si mesmo e no paciente; Daniel retraça ainda a biografia de Freud com alguns curiosos pormenores, como o fato de ele ter sido "bolsista" em Paris para estudar com Charcot... Retraça, dessa feita, pontos a que ele mesmo, Daniel, e muitos outros aventureiros do universo inconsciente, se identificariam em relação às façanhas de um estudioso, artista, feiticeiro e curandeiro da palavra, como poderiam anunciar seus detratores. Afinal, ainda hoje a psicanálise causa estranheza naqueles que são impermeáveis a um saber visto como "oculto", um sabido que não se quer saber, porque "dói" sabê-lo, embora a escuta clínica possa "curar" no sentido de libertar... Ciente do peso dessa dor - preço pago pela revelação e pelo contato com aquilo que está, respectivamente, recalcado e clivado - mesmo assim, Daniel Kupermann desconstrói estereótipos, procurando "desterritorializar" a psicanálise. Reafirma a importância de o trabalho analítico se constituir num encontro lúdico, para além de um labor em que o sofrimento seria exclusividade. A clínica, a formação e, também, a transmissão podem ser libertárias, não só pelo reconhecimento das e pela 'quase recomendação' às "transferências nômades" ou "transferências cruzadas", como postulou no seu primeiro livro (Kupermann, 2014), mas ainda pela capacidade e ousadia em brincar não só com pacientes, mas, também, com aprendizes, como atesta sua obra já tornada referência — "Ousar Rir" (Kupermann, 2003) - em que resgata a categoria do "humor" (Witz) para pensar uma psicanálise mais leve e criativa.

Sem perder o rigor teórico que marca suas pesquisas, em momentos tocantes como a publicação de uma aula magna dada aos estudantes de psicologia da Universidade de São Paulo, Daniel nos presenteia com a desenvoltura de um professor experimentado que abdica do tom rebuscado da academia, empregando, em alguns capítulos, uma linguagem despretensiosa que permite aos leigos e iniciantes se apaixonarem e se identificarem com os sonhos de Freud, assim como ele mesmo confessa ter se identificado, sobretudo em um momento derradeiro de confronto com a própria "castração": um professor que perde a voz. Ao se despir de uma linguagem tecnocientífica, aproxima os 
jovens estudantes, candidatos potenciais a atualizar a práxis psicanalítica, de seu próprio desejo de cuidar com alegria, de fato, a única coisa que podemos transmitir. Ele dá o merecido destaque ao papel atual da Universidade no aprofundamento em pesquisas voltadas ao campo do inconsciente, importante celeiro e fonte de continuidade às necessárias teorizações que renovam e mantêm viva a dinâmica clínica. A forma como "coloca" a psicanálise, seja na Universidade, seja nas conferências proferidas em sociedades e em congressos, retomadas em prosa nesse livro, demonstram a potência da transmissão autoimplicada, posto que não enrijecida por um academicismo frio e hermético, nem tampouco por uma arrogância normativa, usual nas sociedades ortodoxas em que a psicanálise perdeu a vitalidade transformadora para se transformar em mais uma técnica adaptativa prorrogada ad infinitum por seguidores do "discurso do mestre" (Lacan, 1969-1970/1992).

Ao passo que, hoje em dia, ao contrário de certo "envelhecimento" da psicanálise freudiana em certas escolas filiadas à International Psychoanalytical Association, cuja pequena massa de cabelos brancos se mantêm fiel ao legado da tradição, vemos uma profusão do saber lacaniano, com escolas lotadas, principalmente de jovens, como é o caso da École da la Cause Freudienne e suas derivações em diversos países. Contudo, os caminhos hegemônicos não são os únicos passíveis de se trilhar, embora essa escolha contenha riscos, sobretudo o da autoimplicação. Daniel realça a força de uma crítica necessária contra a burocratização das "análises didáticas", questionando inclusive certas exigências de "formação" que já não têm cabimento em nossos dias. Também toca na ferida dos equívocos ligados ao dispositivo do "passe", com certa tendência a estimular a adesão a uma espécie de 'igreja', algo que o próprio Lacan já havia ironicamente alertado, reconhecendo-se como o "último freudiano". Daniel aponta esses desvelos sem desmerecer o importante impulso que Lacan deu para refundar a clínica e fincá-la de vez nos séculos XX e XXI, haja vista o fato de referendar esse incontornável autor em diversos de seus artigos. Mesmo bebendo na fonte de alguns trabalhos de Jacques Lacan, Daniel Kupermann insiste num caminho diferente, com origem nos primórdios das confrontações psicanalíticas. Ele advoga, de certa forma, por uma pluralidade de referências, revitalizando com élan et savoir-faire uma atuação marcada pela presença de grandes psicanalistas do cenário brasileiro. A singularidade de seu "estilo de cuidar" (Ogden, 2007) potencializa uma vertente transgressiva, no sentido de questionadora, e, bem-humorada, no sentido de inventiva, embora não menos consciente de nossa própria vulnerabilidade enquanto terapeutas num mundo sans repairs. 


\section{RESENHAS BIBLIOGRÁFICAS}

Desde a entrada do livro, somos levados pela mão do autor a conhecer as controvérsias pertinentes à construção de um modo crítico e não ortodoxo de conduzir a clínica, trazendo novos ares a um suposto consultório "neutro", padronizado e, por vezes, "violento", cujos efeitos iatrogênicos se encontram tanto num "freudismo" quanto num "lacanismo" estereotipados. A perspectiva teórica escolhida como caminho díspar, inspirada no enfant terrible da psicanálise, partiu da experiência ferencziana com pacientes difíceis. Sándor Ferenczi deu uma visada original à psicanálise, tornando-a mais profícua em relação aos sintomas dos pacientes que não respondiam ao modo tradicional de se conduzir a cura, ou seja, pelas regras clássicas da "livre-associação", pelo "princípio de abstinência" e pela "análise das resistências" nos embates transferenciais. Em Estilos do cuidado..., podemos vislumbrar como a leitura ferencziana amplia as condições de cuidado dos que não respondem bem à técnica do "corte lógico", já que alguns pacientes experimentam essa prática como uma forma de violência. Se o "corte lógico" é ímpeto fundamental para prosseguir com eficácia renovada a clínica com histérica/o/s e, principalmente, com obsessivo/a/s, não é recomendado com os pacientes excessivamente traumatizados.

Portanto, com uma "pegada" teórica ferencziana e winnicottiana, também inspirada em autores da tradição psicanalítica brasileira, principalmente, na maestria clínica de Luís Claudio Figueiredo (1996; 2007; 2008), Daniel desvenda o mecanismo da "clivagem do ego" como forma de "desautorização" (Verleulung) vivida na relação com o outro. O autor descreve a formulação ferencziana do traumático: um "terceiro" não reconhece a dor relatada por um sujeito em estado de dúvida e angústia. Após a vivência de um abuso sexual ou de uma violência, a criança busca ajuda em alguém em que confia para relatar uma situação potencialmente conflituosa, buscando dar sentido a essa vivência junto ao interlocutor eleito. Contudo, o destinatário de sua enunciação não reconhece o relato como sendo verdadeiro, desqualificando e/ou invalidando aquilo que foi dito, logo, rompendo um laço de confiança. O cerne do trauma, dessa forma, reside nesse segundo tempo de "desautorização", muito mais do que na vivência de violência e/ou abuso sexual em si, já que o sujeito torna-se impedido de atribuir um sentido compartilhado àquilo que sofreu. Assim, a leitura ferencziana da "negação" ou "desautorização"1 (Verleugnung) — relacionada ao "fetichismo" em Freud

\footnotetext{
${ }^{1}$ Usualmente traduzida por “desmentido" na tradução brasileira (Ferenczi, 1992).
} 
(1927/2004) - relança toda uma discussão sobre o "traumático" e o papel sensível das figuras de confiança: pais, professores, terapeutas. Remetendo à deontologia psicanalítica, a "saúde", a "empatia" e a "hospitalidade" do terapeuta implicam no fato de o analista se situar, muitas vezes, nesse lugar de "autorização" e reconhecimento do sofrimento do outro, o que depende essencialmente da qualidade da análise do analista. A sensibilidade emerge, portanto, daquilo que ele consegue escutar sem rechaçar. Dito de outra maneira, não basta interpretar o sujeito em relação às formações enigmáticas do sintoma, nem tampouco cortar abruptamente suas repetições na esperança de que o analisando se dê conta sozinho de sua dor e, num passe de mágica, legando-o à sua própria razão solipsista, por ventura, impregnada pela pulsão masoquista.

Assim, apesar de ter sido alijado por quase meio século da história oficial da psicanálise, Ferenczi foi pioneiro em postular a necessidade de ir fundo na análise do analista, principalmente em seus pontos cegos referidos à agressividade e à transferência negativa, acentuando os pontos nevrálgicos daquilo que reverbera na relação sensível com o outro. Piera Aulagnier (1975) também ressaltou a questão de haver certa inabilidade no manejo clínico ao denunciar a interpretação como uma forma de violência. Não é à toa que essa autora fundou seu próprio caminho. Segundo ela, desde os momentos mais arcaicos da vida psíquica, o Eu está submetido aos mandos e desmandos de um "porta-voz", pois pode existir certa brutalidade naquele que se arvora a nomear os sentimentos e, principalmente, a compreender a dor e o sofrimento psíquico do outro. A figura materna é, por excelência, esse "porta-voz" que interpreta, bem ou mal, os anseios que o bebê ainda não é capaz de exprimir. A forma como a mãe arbitra sobre o desejo infantil é considerada por essa autora (Aulagnier, 1975) como uma forma de "violência primária". Nesse sentido, em toda tradição psicanalítica francesa, reconhece-se essa "violência da linguagem" em que o que se diz nem sempre condiz com uma suposta realidade da pulsão infantil, sempre subrrepresentada. Pouco a pouco esse "porta-voz" inicial, o sujeito que está ao lado (Nebenmensch) no momento do desemparo, vai sendo substituído por outras figuras de confiança que podem vir a corroborar a experiência subjetiva ou, do contrário, a trair a confiabilidade daquele que se angustia e busca ajuda. Em suma, nem sempre um "porta-voz" - seja um dos pais, seja um mestre, seja um analista — é capaz de capturar e traduzir em palavras o sofrimento alheio, e, quanto a isso, todos devemos estar atentos, principalmente, os psicanalistas-professores-pesquisadores, que têm tanto destaque em nosso tempo. Esses mestres do entender e do explicar são os que precisam ainda mais do cuidado na supervisão para não 


\section{RESENHAS BIBLIOGRÁFICAS}

deslizar para o "discurso do mestre" (Lacan, 1969-1970/1992) na clínica. Até porque nem sempre o analista está preparado para "sentir com" o paciente: um requisito fundamental à "hospitalidade" clínica, como preconiza Kupermann a partir do conceito derrideano. Cabe a nós, artesãos do cuidado com o sofrimento recalcado, clivado, cindido, escamoteado, poder receber, suportar, aceitar, manejar e, mesmo, regredir, brincar e rir — "rir com", jamais "rir do" paciente. Da postura hierárquica de um "porta-voz" (ou de um 'corta-voz'), típicas das posições paterna mas, também, materna adotadas ao longo das transformações da clínica psicanalítica, pode bem advir uma postura mais horizontal, ligada à estética e às políticas da amizade (Derrida, 1994; Gondar, 2012; Oliveira, 2012; Arreguy \& Coelho, 2017). Em suma, para poder cuidar, precisamos estar bem amparados em nossos meios e por nossos pares. E se cuidamos dos analistas, precisamos igualmente cuidar de nossas instituições. Daniel Kupermann aborda essas questões, inclusive, relembrando de seus passos iniciais como psicanalista num hospital público. Aguardemos agora que, para além da teoria da clínica, o autor nos brinde com novos livros, sobretudo, que revelem seu próprio sucesso no manejo e no suporte, com toda graça de que é capaz. Que venham as histórias dos casos clínicos, em que o humor certamente opera nos bastidores.

\section{Referências}

Arreguy, M. E., \& Coelho, M. F. (2017). Horizontalizade, dizer verdadeiro e a escuta psicanalítica construída com educadores. In M. R. Pereira. (Org.), Os sintomas na educação de hoje: que fazemos com isso? Belo Horizonte, MG: Scriptum.

Aulagnier, P. (1975). Violence de l'interprétation. Paris: PUF.

Derrida, J. (1994). Politiques de l'Amitié. Paris: Galilée.

Ferenczi, S. (1992). Obras Completas. São Paulo: Martins Fontes.

Figueiredo, L. C., \& Coelho Junior, N. (2008). Ética e técnica em psicanálise. São Paulo, SP: Escuta.

Figueiredo, L. C. (1996). A invenção do psicológico: quatro séculos de subjetivação. São Paulo, SP: Educ/Escuta.

Figueiredo, L. C. (2007). Confiança: a experiência de confiar na clínica psicanalítica e no plano da cultura. Revista Brasileira de Psicanálise, 41(3), 69-87.

Freud, S. (2004). O fetichismo. In Escritos sobre a psicologia do inconsciente (vol. 3). Rio de Janeiro, RJ: Imago. (Trabalho original publicado em 1927). 
Gondar, J. (2012, jul./dez.). Ferenczi como pensador político. Cadernos de Psicanálise - Círculo Psicanalítico o Rio de Janeiro, 34(27), 193-210.

Kupermann, D. (2003). Ousar rir: humor, criação e psicanálise. Rio de Janeiro, RJ: Civilização Brasileira.

Kupermann, D. (2008). Presença sensível: cuidado e criação na clínica psicanalítica. Rio de Janeiro, RJ: Civilização Brasileira.

Kupermann, D. (2014). Transferências cruzadas: uma história da psicanálise e suas instituições. São Paulo, SP: Escuta.

Lacan, J. (1992). O seminário. Livro 17. O avesso da psicanálise. Rio de Janeiro, RJ: Jorge Zahar. (Trabalho original publicado em 1969-1970).

Ogden, T. (2007). Elements of analytic style: Bion's clinical seminars. International Journal of Psychoanalisis, 88, 1185-1200.

Oliveira, L. R. P. de. (2012). O sentido da amizade em Ferenczi: uma contribuição à clínica psicanalítica. Rio de Janeiro, RJ: UAPÊ, 2012.

Citação/Citation: Arreguy, M. E. (2018, março). Do trauma à ternura: os fundamentos da clínica do cuidado. Resenha do livro Estilos do cuidado - a psicanálise e o traumático. Revista Latinoamericana de Psicopatologia Fundamental, 21(1), 182-188. http://dx.doi. org/10.1590/1415-4714.2018v21n1p182.12

Editores do artigo/Editors: Profa. Dra. Sonia Leite

Recebido/Received: 17.12.2017 /12.17.2017 Aceito/Accepted: 20.1.2018 / 1.20.2018

Copyright: (C) 2009 Associação Universitária de Pesquisa em Psicopatologia Fundamental/ University Association for Research in Fundamental Psychopathology. Este é um artigo de livre acesso, que permite uso irrestrito, distribuição e reprodução em qualquer meio, desde que o autor e a fonte sejam citados / This is an open-access article, which permits unrestricted use, distribution, and reproduction in any medium, provided the original authors and sources are credited.

\section{Marília Etienne Arreguy}

Professora do Programa de Mestrado e Doutorado em Educação da Universidade Federal Fluminense - UFF (Niterói, RJ, Br); Pesquisadora convidada na École Doctorale de Recherches en Psychanalyse et Psychopathologie da Université Paris Diderot/Sorbonne Cité; Pós-doutoranda na Université Paris 8. mariliaetienne@id.uff.br

This is an open-access article, which permits unrestricted use, distribution, BY-NC and reproduction in any medium for non-commercial purposes provided the original authors and sources are credited. 